Article

\title{
Interaction Assessment and Stability Analysis of the MMC-Based VSC-HVDC Link
}

\author{
Saman Dadjo Tavakoli * (D), Eduardo Prieto-Araujo (1), Enric Sánchez-Sánchez \\ and Oriol Gomis-Bellmunt $\mathbb{D}$
}

CITCEA-UPC, Department of Electrical Engineering, Universitat Politècnica de Catalunya, Av. Diagonal 647, 08028 Barcelona, Spain; eduardo.prieto-araujo@upc.edu (E.P.-A.); enric.sanchez.sanchez@upc.edu (E.S.-S.); oriol.gomis@upc.edu (O.G.-B.)

* Correspondence: saman.dadjo@upc.edu

Received: 28 February 2020; Accepted: 17 April 2020; Published: 21 April 2020

\begin{abstract}
This paper investigates the dynamic behavior of a modular multi-level converter (MMC)-based HVDC link. An overall state-space model is developed to identify the system critical modes, considering the dynamics of the master MMC and slave MMC, their control systems, and the HVDC cable. Complementary to the state-space model, an impedance-based model is also derived to obtain the minimum phase margin (PM) of the system. In addition, a relative gain array (RGA) analysis is conducted to quantify the level of interactions among the control systems of master and slave MMCs and their impacts on stability. Finally, with the help of the results obtained from the system analysis (eigenvalue, phase margin, sensitivity, and RGA), the system dynamic performance is improved.
\end{abstract}

Keywords: HVDC; MMC; mutual interactions; small-signal analysis; state-space model

\section{Introduction}

Modular multi-level converter (MMC) has emerged as the preferred choice for voltage source converter (VSC)-based HVDC systems mainly due to low losses, low harmonic distortion, scalability, and redundancy [1,2]. However, the control design for an MMC is more challenging as compared to a conventional two-level VSC, which is due to the extra control actions required for the regulation of the internal energy balances. The different control schemes proposed in the literature can be classified as follows. First, the non-energy-based control method (also known as uncompensated modulation) in which the internal energy of the MMC is not explicitly regulated [3-7]. This control approach is asymptotically stable but the transient response of MMC depends on the converter impedance rather than being dictated by the control actions, which leads to slow and undesirable dynamics [8]. Moreover, it imposes parasitic circulating current components that require additional current control loops to attenuate them [3]. An alternative approach is to implement an energy-based method, also known as compensated modulation or closed-loop modulation [8-11]. This control method does not generate parasitic voltage components, but energy controllers are required to ensure an asymptotically stable system [12].

Considering the energy-based method, several control loops are required to achieve certain objectives. Commonly, these control loops are structured to form a cascade control in which the outer control loops generate references for the inner loops. The outer control loops involve the energy control, DC voltage control (in case of master MMC), and active power control (in case of slave $\mathrm{MMC}$ ), which provide references for the grid current control and the additive current (also known as circulating current) control [8]. The design and tuning of these control loops are challenging since there is a strong coupling among them $[13,14]$. For instance, a change in the energy reference of the slave 
MMC would cause a transient in the DC voltage of the master MMC, and vice versa. These interactions can reduce the stability margin of the system and even lead to instability [15].

Hence, in a system with strong coupling among control variables, the design and tuning of a control loop needs to be conducted such that the overall stability margin of the entire system is maintained and an elevated level of interactions among control loops is avoided [16]. In fact, if the level of interactions among control loops is not considered during the design of a control loop, the attempts to obtain a locally optimal control loop with fast response and suppressed over/undershoot may force the entire system to operate in a high interaction conditions with reduced stability margin.

In order to evaluate the system stability and the level of the interactions among control loops, a linear model of the MMC-based HVDC system is needed, which can be derived using one of the following modeling approaches:

- State-space modeling based on $d q$ transformation $[8,11,14,17]$ : in this modelling approach, the electrical circuit equations of an MMC are commonly transformed to $d q$-frame and expressed in state-space equations. These equations are interconnected to the state-space equations of the control loops based on the similar input/output signals in order to formulate an overall linear model of an MMC. Although this modeling approach offers a high level of modularity, the inclusion of the circulating current harmonics in the modeling is challenging [11].

- State-space modeling based on the dynamic phasor [18-22]: this modeling approach is also based on the state-space modeling techniques, but the system is in $a b c$-frame. It is a suitable modeling method for studying the impact of harmonics on the system stability [18].

- Impedance-based modeling [23-25]: in this modeling approach, the impedance of the MMC at the AC and DC sides are analytically computed. A major advantage of this method is the ability to judge the system stability margin [23].

Once the linear model of an MMC is derived using one of the above-mentioned methods, the model should be extended to include the dynamics of other system components, such as the HVDC cable, to formulate the overall linear model of the system suitable for stability assessment and interaction analysis. Several studies have only focused on the linear model of a single MMC and, to some extent, ignored the dynamics of either DC or AC networks. In [26], a simplified model of an MMC is developed aiming for adopting a sliding mode control in $a b c$-frame, which simplifies the complexity of the $d q$-frame transformation related to the MMC circulating current. The linear model of an MMC is derived for the system stability assessment in [6], and the control system is designed based on the linear model [27]. However, the linear model does not include the dynamics of the slave MMC. In [14], a linear state-space model of an HVDC system is derived to analyze the system transient response, suggesting alternative controllers to improve the converter dynamic behavior. However, it does not provide information on the system phase margin (PM) and the interactions among the control loops are neither addressed.

In this paper, a procedure is suggested to include two key global aspects of an MMC-based HVDC link in the control system design: (1) the overall PM of the system, and (2) the level of interactions among the control loops. Two linear models that accurately capture the dynamics of the master and slave MMCs, their control systems, and the HVDC cable are developed to identify the control loop with the most adversary impact on the system overall dynamics, and design this control loop with the consideration of the overall performance of the system, rather than only focusing on the local performance requirements such as the maximum over/undershoot.

The rest of the paper is organized as follows. In Section 2, the configuration of the HVDC link and the control system of MMC are described. In Section 3, the state-space equations of the complete system are derived and linearized, which are later used in Section 4 to build an overall state-space model of the system. In Section 5, complementary to the overall state-space model, an impedance-based model is derived to provide additional insight into the dynamic behavior of the HVDC link. Once the two linear models are derived, the system stability is studied and the critical modes are identified through 
an eigenvalue and participation factors analysis in Section 6. Moreover, the system minimum PM is calculated through an impedance-based analysis using the Nyquist plot, and the level of interactions among control loops is studied using a frequency-dependent relative gain array (RGA) analysis. Finally, in Section 7, based on the results achieved from the system analyses, the stability of the system is improved by tuning the DC voltage control loop.

\section{System Description}

A typical HVDC link between two AC networks is shown in Figure 1. In such configuration, the master MMC regulates DC voltage while the slave MMC controls active power exchange [27]. Either AC voltage or reactive power can be regulated at both ends.

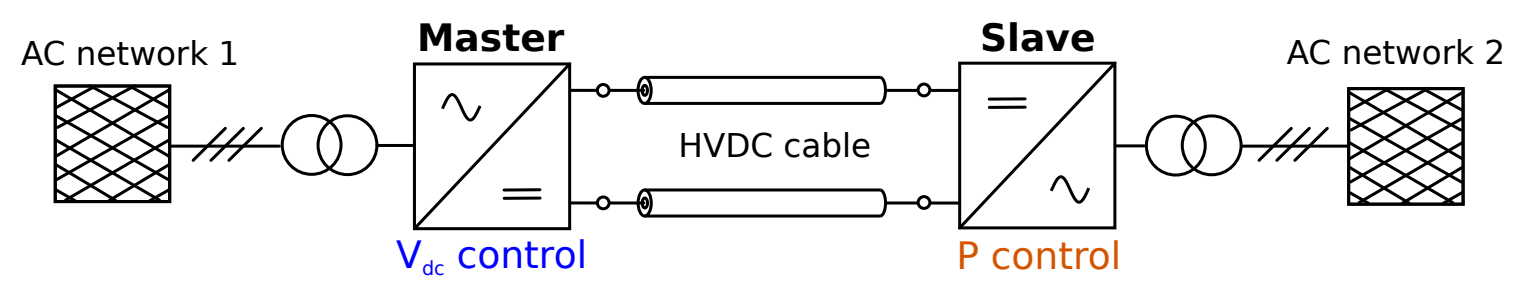

Figure 1. Multi-level converter (MMC)-based HVDC link.

The average-value model of the MMC structure connected to an AC network is presented in Figure 2. Compared to the detailed model, the IGBTs of submodules are not explicitly modeled and the MMC dynamics are represented by controlled voltage and current sources [2,28,29]. In [30], it has been shown that the average-value model accurately replicates the dynamic performance of the detailed model, and it is significantly more efficient for simulation time steps.
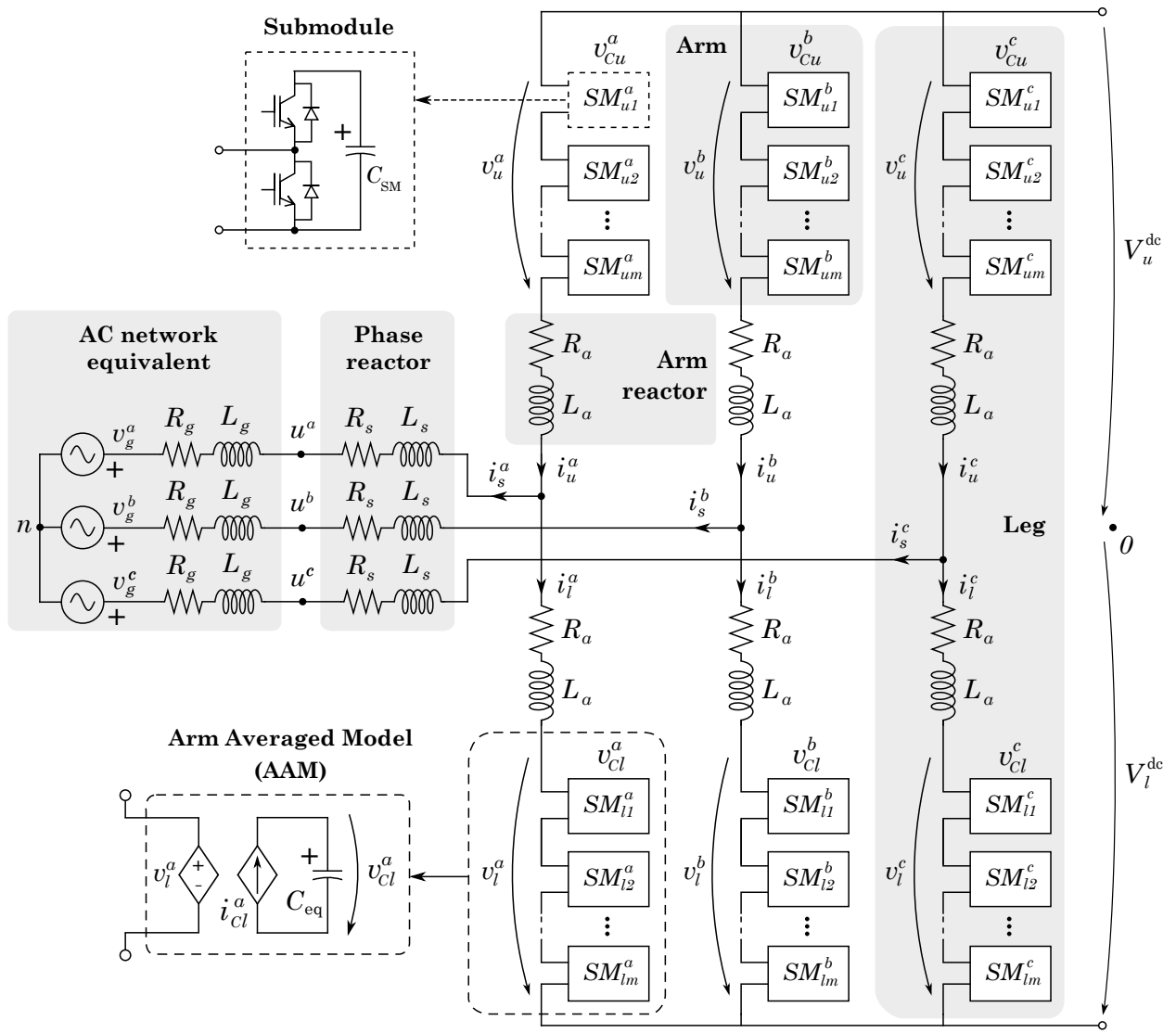

Figure 2. Average-value model (AVM) of MMC connected to an AC network. 
Referring to Figure 2, the MMC consists of six arms, each of them contains $N_{\text {arm }}$ half-bridge submodules with a capacitance $C_{S M}$ and an arm reactor connected in series. The three legs, corresponding to three phases, can be divided into upper and lower arms. The six arms synthesize the required $\mathrm{AC}$ and DC voltages to achieve the desired power exchange between the AC and DC sides. The control system of both MMCs is based on the energy-controlled approach and presented in Figure 3. The grid side current controller tracks the current references sent by the outer control loop. In the case of the master MMC, the DC voltage outer control loop provides the $q$-axis current reference, whereas, in the slave MMC, it is provided by the active power control loop. In both cases, the $d$-axis current reference is given by the reactive power control loop. In addition, the energy balancing and total energy control send the circulating current reference for the inner current controller. Furthermore, a Phase Locked Loop (PLL) tracks the AC voltage in the point of connection with the AC network. The outputs of both the current control systems (grid side and circulating) are used to generate the six-arm voltages. Finally, the modulation and cell-balancing algorithm are responsible for generating the required voltage through communication with the submodule switches.

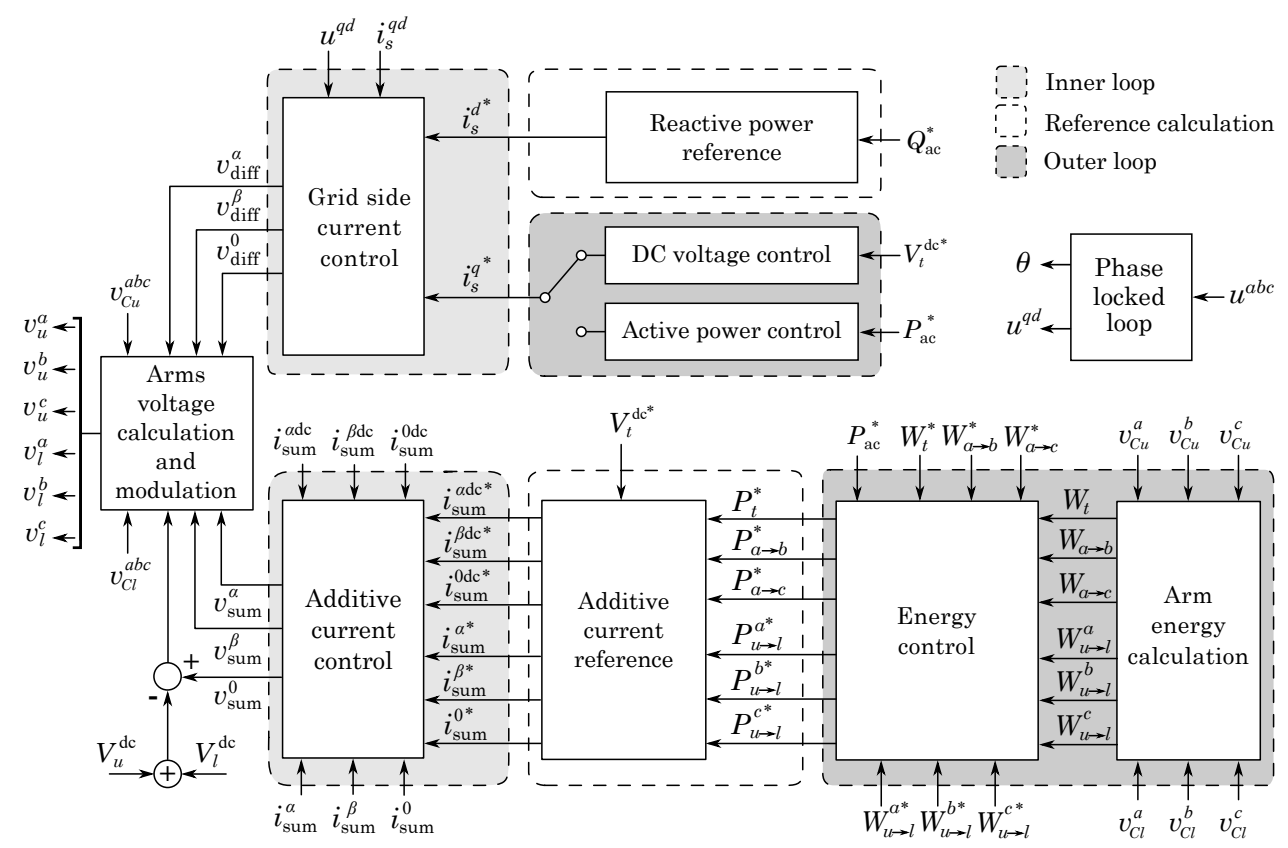

Figure 3. MMC energy-based control system.

\section{System Modeling}

In this section, a non-linear model of an MMC-based HVDC link is derived. This non-linear model is then linearized to obtain an overall linear model of the system. More details and explanations are provided in [8].

\subsection{Modular Multilevel Converter (MMC)}

Figure 2 shows the MMC average model electrical circuit. The equations per phase are

$$
\begin{aligned}
& V_{u}^{\mathrm{dc}}-v_{u}^{j}-v_{g}^{j}-v_{n}= \\
& R_{a} i_{u}^{j}+L_{a} \frac{d i_{u}^{j}}{d t}+\left(R_{s}+R_{g}\right) i_{s}^{j}+\left(L_{s}+L_{g}\right) \frac{d i_{s}^{j}}{d t} \\
& -V_{l}^{\mathrm{dc}}+v_{l}^{j}-v_{g}^{j}-v_{n}= \\
& \quad-R_{a} i_{l}^{j}-L_{a} \frac{d i_{l}^{j}}{d t}+\left(R_{s}+R_{g}\right) i_{s}^{j}+\left(L_{s}+L_{g}\right) \frac{d i_{s}^{j}}{d t},
\end{aligned}
$$


where, $R_{a}$ and $L_{a}$ are arm resistance and inductance, $R_{S}$ and $L_{S}$ are AC grid filter resistance and inductance, $V_{u}^{\mathrm{dc}}$ and $V_{l}^{\mathrm{dc}}$ are upper and lower voltages of the HVDC link. The AC grid current and Thévenin voltage are, respectively, $i_{s}^{j}$ and $v_{g}^{j}$, while the voltages applied by the upper and lower arms are $v_{u}^{j}$ and $v_{l}^{j}$. The currents flowing through the upper and lower arms are indicated by $i_{u}^{j}$ and $i_{l}^{j}$, respectively.

The following variable change is common in MMC modeling [8]

$$
\left\{\begin{array} { l } 
{ v _ { \text { diff } } ^ { j } \triangleq \frac { 1 } { 2 } ( - v _ { u } ^ { j } + v _ { l } ^ { j } ) } \\
{ v _ { \text { sum } } ^ { j } \triangleq v _ { u } ^ { j } + v _ { l } ^ { j } } \\
{ i _ { \text { sum } } ^ { j } \triangleq \frac { 1 } { 2 } ( i _ { u } ^ { j } + i _ { l } ^ { j } ) } \\
{ R \triangleq R _ { s } + R _ { g } + \frac { R _ { a } } { 2 } } \\
{ L \triangleq L _ { s } + L _ { g } + \frac { L _ { a } } { 2 } }
\end{array} \quad \left\{\begin{array}{l}
v_{u}^{j}=-v_{\text {diff }}^{j}+\frac{1}{2} v_{\text {sum }}^{j} \\
v_{l}^{j}=v_{\text {diff }}^{j}+\frac{1}{2} v_{\text {sum }}^{j} \\
i_{u}^{j}=\frac{1}{2} i_{s}^{j}+i_{\text {sum }}^{j} \\
i_{l}^{j}=-\frac{1}{2} i_{s}^{j}+i_{\text {sum }}^{j}
\end{array}\right.\right.
$$

where $v_{\text {diff }}^{j}$ is the differential voltage, approximately equal to the AC voltage at the point of connection and $i_{\text {sum }}^{j}$ is the additive current circulating from the upper to the lower arm of the leg $j(j=a, b, c)$. The additive voltage is indicated by $v_{\text {sum }}^{j}$ and it is approximately equal to the sum of the DC poles voltages. Then, adding and subtracting (1) and (2) and using the variable change given by (3) would lead to

$$
\begin{aligned}
& \frac{1}{2}\left(V_{u}^{\mathrm{dc}}-V_{l}^{\mathrm{dc}}\right)+v_{\mathrm{diff}}^{j}-v_{g}^{j}-v_{n}=R i_{s}^{j}+L \frac{d i_{s}^{j}}{d t} \\
& v_{\text {sum }}^{j}-\left(V_{u}^{\mathrm{dc}}+V_{l}^{\mathrm{dc}}\right)=-2 R_{a} i_{\text {sum }}^{j}-2 L_{a} \frac{d i_{\text {sum }}^{j}}{d t} .
\end{aligned}
$$

Equations (4) and (5) are decoupled and only contain a single derivative term ( $i_{s}^{j}$ and $i_{\text {sum }}^{j}$ ). Hence, they are suitable for state-space representation. The current $i_{\text {sum }}^{j}$ contains AC and DC terms which impact the performance of the control system in various aspects. The DC term of $i_{\text {sum }}^{j}$ can be transformed into $(\alpha \beta 0)$ frame. The zero component is used for the control of the power flow into the DC grid, while the $(\alpha \beta)$ components regulate the internal power exchange between legs. The AC term of $i_{\text {sum }}^{j}$ contains $(+-0)$ sequences. The zero sequence is controlled to zero, avoiding AC distortion in the DC grid, whereas (+-) sequences can be used to regulate the internal power exchange between upper and lower arms of each leg. A comprehensive discussion can be found in [8].

Since $i_{\text {sum }}^{j}$ contains AC terms with various frequencies, the transformation into $(q d)$ frame becomes complicated. However, these components are relevant for the DC pole imbalances studies [31]. Considering only the DC term of $i_{\text {sum }}^{j}$, the system becomes suitable for linearization. Using the following definitions

$$
V_{\mathrm{off}}^{\mathrm{dc}} \triangleq \frac{1}{2}\left(V_{u}^{\mathrm{dc}}-V_{l}^{\mathrm{dc}}\right), \quad V_{t}^{\mathrm{dc}} \triangleq V_{u}^{\mathrm{dc}}+V_{l}^{\mathrm{dc}}
$$

combined with (4) and (5), yields

$$
\begin{aligned}
& v_{\mathrm{diff}}^{a b c}-v_{g}^{a b c}+\left(V_{\mathrm{OFF}}^{\mathrm{dc}}-v_{n}\right)\left(\begin{array}{lll}
1 & 1 & 1
\end{array}\right)^{T}=R \mathcal{I}_{3} i_{s}^{a b c}+L \mathcal{I}_{3} \frac{d i_{s}^{a b c}}{d t} \\
& v_{\mathrm{sum}}^{\alpha \beta 0 \mathrm{dc}}-V_{t}^{\mathrm{dc}}\left(\begin{array}{lll}
0 & 0 & 1
\end{array}\right)^{T}=-2 R_{a} \mathcal{I}_{3} i_{\mathrm{sum}}^{\alpha \beta 0 \mathrm{dc}}-2 L_{a} \mathcal{I}_{3} \frac{d i_{\mathrm{sum}}^{\alpha \beta 0 \mathrm{dc}}}{d t},
\end{aligned}
$$

where $\mathcal{I}_{\mathbf{n}}$ is an identity matrix of order $n$. Combining (7) and (8) and considering only the DC term of $i_{\text {sum }}^{j}$, three linear state-space equations can be derived. The three state variables are $\Delta i_{s}^{q}, \Delta i_{s}^{d}$, and $\Delta i_{\text {sum }}^{0 \mathrm{dc}}$. 


\subsection{Control}

The detailed control system of master/slave MMC is presented in Figure 3. The control system has two main parts detailed above; the grid control and the energy control parts. This control system is used in the nonlinear model of MMCs. However, for the small-signal analysis, it is assumed that the internal energy balance is properly performed; so only a total energy control is required to regulate the zero component of $i_{\text {sum }}^{j}$ [32]. Based on this assumption, the linear model derivation can be simplified while maintaining a high level of accuracy. More details and information regarding the linearization of the PLL and active power equation are provided in [33]. The control system with total energy control is presented in Figure 4. The master MMC has two main closed-loop cascaded control systems, which are DC voltage control $V_{t}^{\mathrm{dc}}$ and total energy control $W_{t 1}$ (which generates the reference for the inner additive current $\left(i_{\mathrm{sum}}^{\mathrm{Odc} *}\right)$ control loop). In the case of slave MMC, it has an active power control loop $P_{2}$ and again a total energy control. For the sake of clarity, the master and slave MMCs are indicated as MMC 1 and MMC 2, respectively.

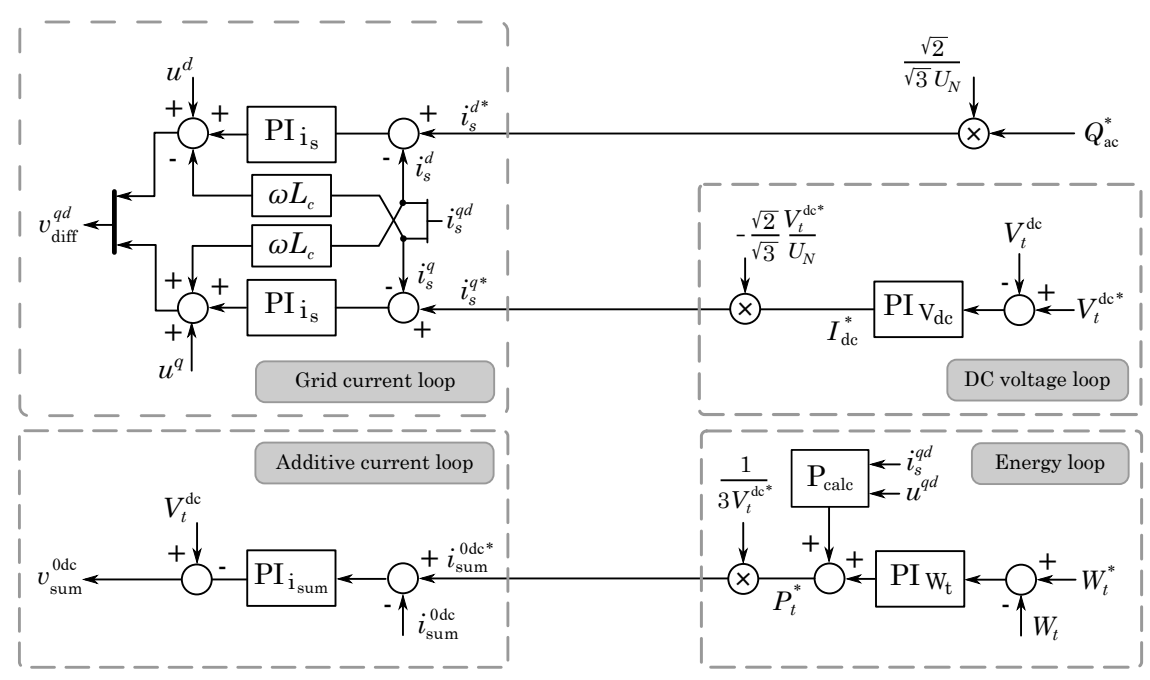

Figure 4. The control system of the master MMC in linear model.

\subsection{HVDC Cable}

The HVDC cable is modeled using a lumped parameters vector fitting method introduced in [34]. In the present case, as it is shown in Figure 5, a five-section model is considered to account for the hyperbolic correction factors, which makes the model more accurate, in particular for long cables.

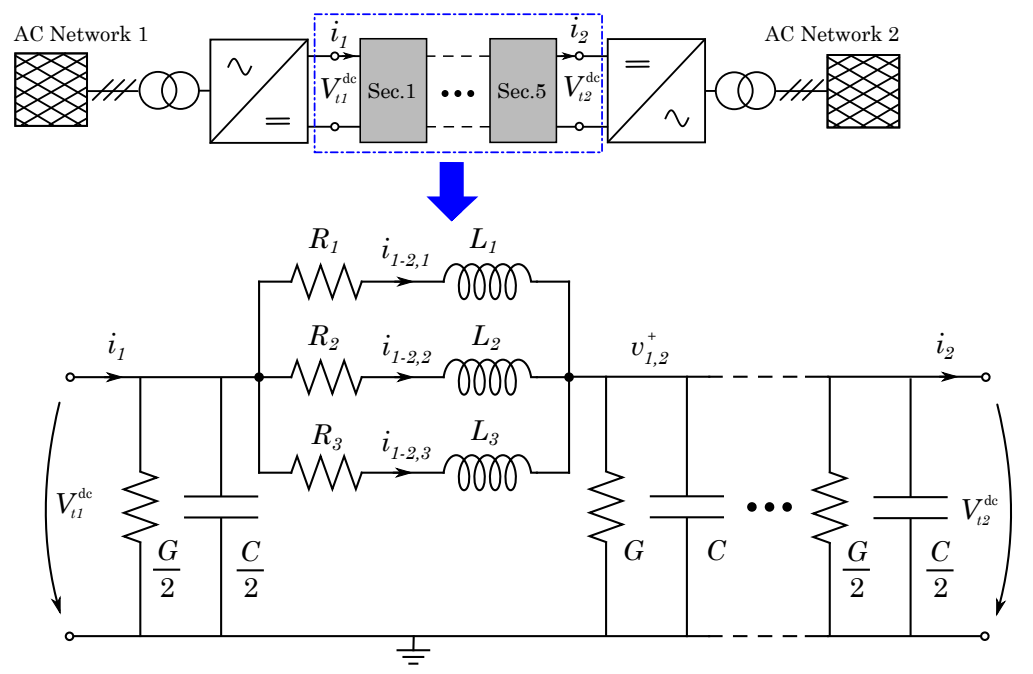

Figure 5. HVDC cable model based on lumped parameters vector fitting method. 


\section{System Overall State-Space Model}

The purpose of this section is to formulate a linear state-space model with the desired input/output pairs, which is suitable for the eigenvalue analysis and the control interactions studies. To obtain this model, the individual state-space models of the master and slave MMCs (MMC 1 and MMC 2), their corresponding control systems, and the HVDC cable are interconnected together based on the similar input/output signal names. The overall state-space model of the HVDC link is given by

$$
\Delta \dot{x}=\mathbf{A} \Delta x+\mathbf{B} \Delta z, \quad \Delta y=\mathbf{C} \Delta x+\mathbf{D} \Delta z,
$$

where $\Delta x$ is a state vector including 43 states of the entire HVDC link, $\Delta z$ is a vector of the system inputs, and $\Delta y$ is a vector of desired outputs. The overall model has 43 state variables and the input/output vectors are selected as follows

$$
\begin{aligned}
& \Delta z=\left(\Delta V_{t}^{\mathrm{dc}}, \Delta P_{2}^{*}, \Delta W_{t 1}^{*}, \Delta W_{t 2}^{*}, \Delta v_{g 1}^{q d}, \Delta v_{g 2}^{q d}, \Delta Q_{1}^{*}, \Delta Q_{2}^{*}\right) \\
& \Delta y=\left(\Delta V_{t}^{\mathrm{dc}}, \Delta P_{2}, \Delta W_{t 1}, \Delta W_{t 2}\right) .
\end{aligned}
$$

The overall linear model of the HVDC link based on the state-space equations is presented in Figure 6. As mentioned earlier, in the linear model, only the total energy control loop of MMCs is considered, assuming that the energy balance between the legs and upper and lower arms is performed in an adequate manner.

The validation of the linear model is performed through a time domain simulation (see Figure 3), in which a detailed energy-based nonlinear model of the MMC with the complete control system is used [8]. First, the active power $\left(P_{2}\right)$ is increased by $20 \%$, then reduced again by similar value. The responses related to various variables in MMC 1 are shown in Figure 7, which confirms the accuracy of the linear model. The parameters of the system can be found in Tables A1 and A2 of the Appendix A.

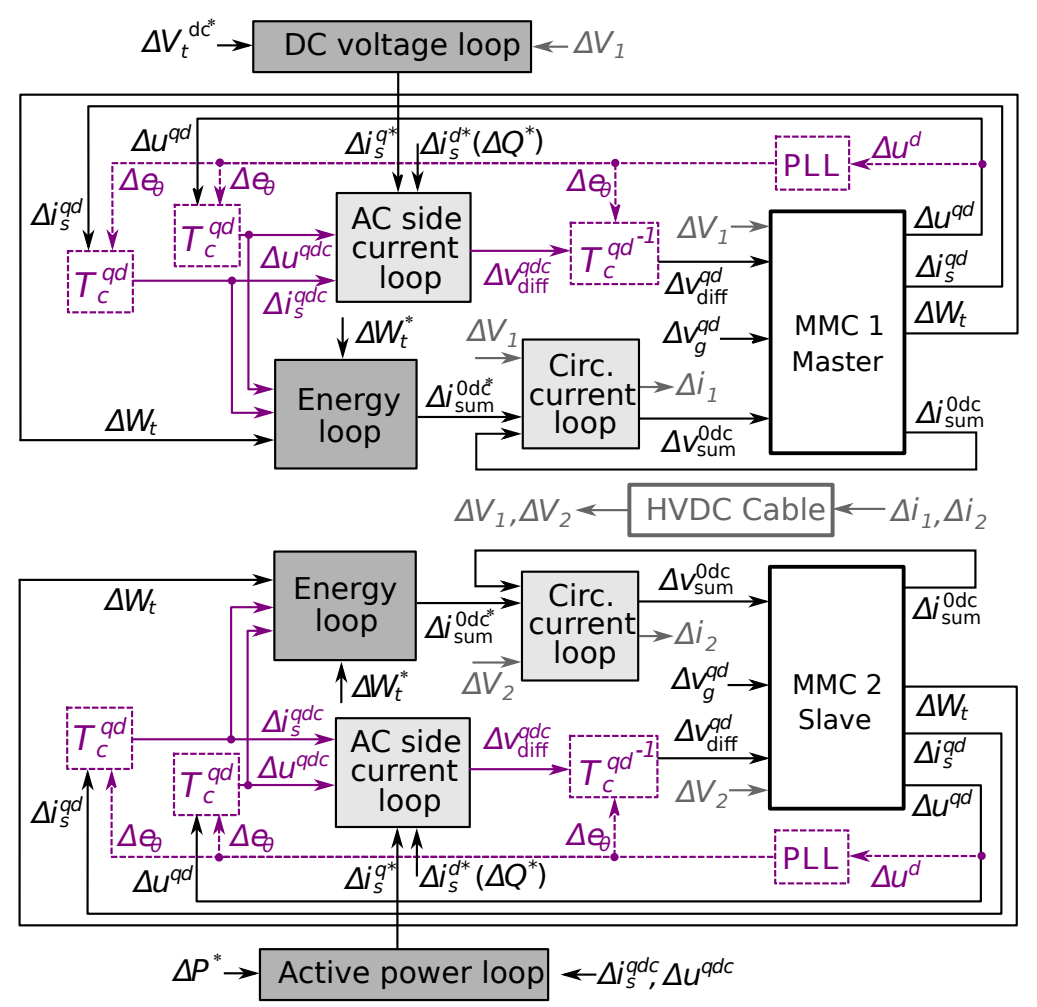

Figure 6. Linear model of the HVDC link with cascaded total energy control loop. 

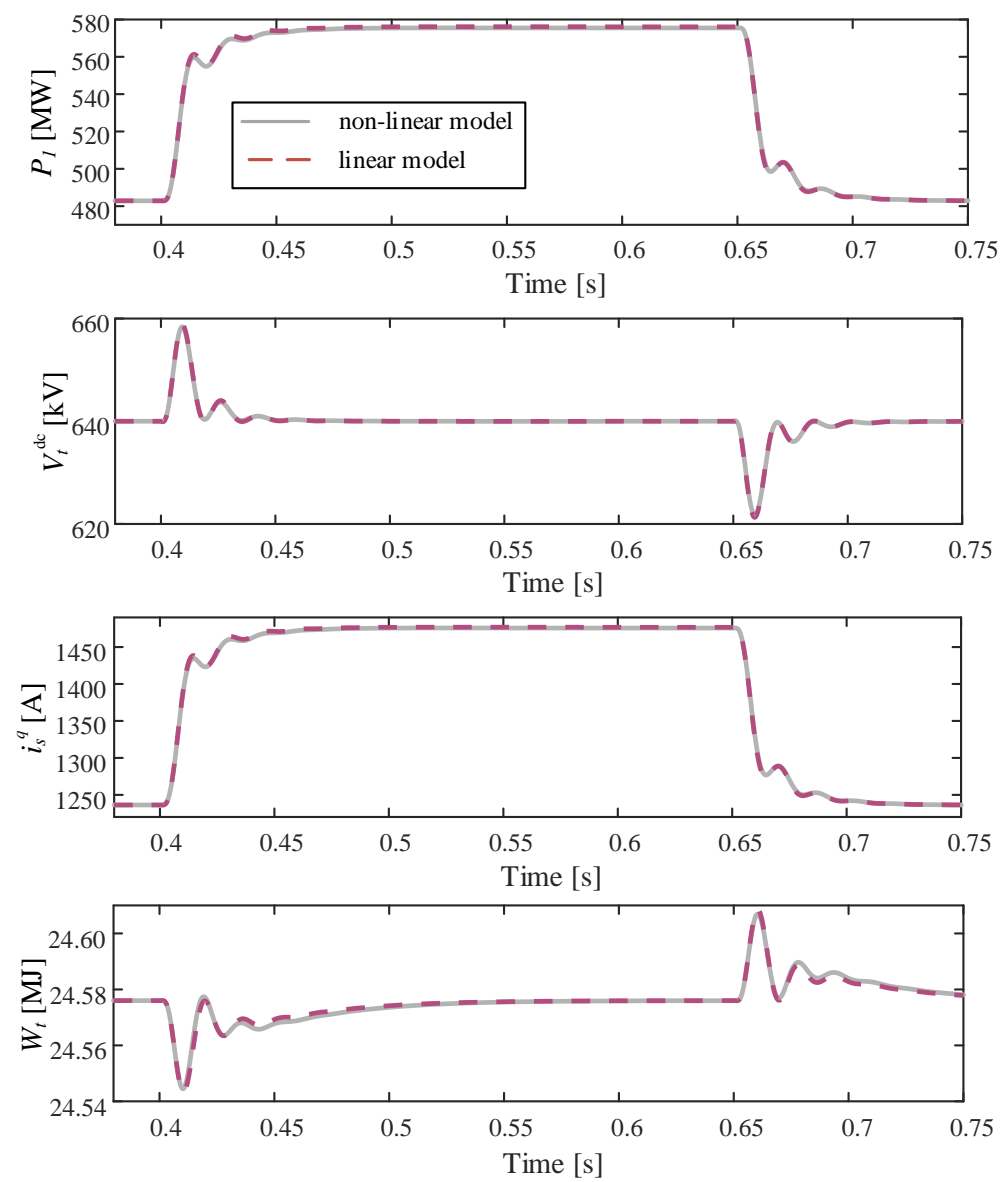

Figure 7. Comparison between the transient responses of the linear and non-linear models.

The multi-input multi-output (MIMO) model presented in Figure 8 is built from the linear model. The complete state-space model is transformed into the Laplace domain and the system transfer function matrix, $T_{s y s}(s)$, relating different input-output variables, is derived.

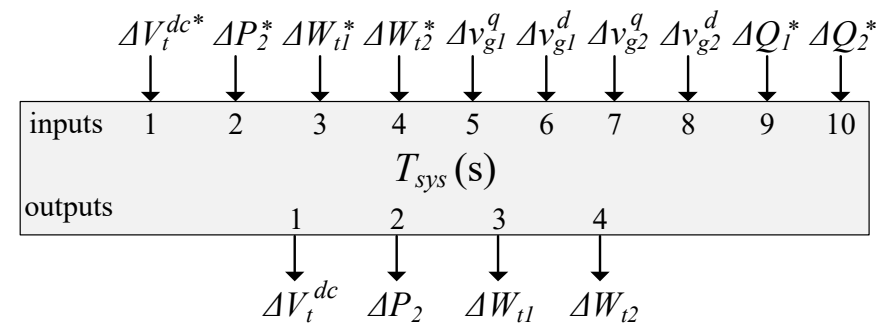

Figure 8. Multi-input multi-output (MIMO) presentation of the linear model of the HVDC link.

\section{System Overall Impedance Model}

The stability of the system can be assessed using the state-space model (eigenvalues of matrix $A$ ). In addition, to get a better insight into the system stability, the impedance model of the system can be used for the Nyquist analysis, giving an overall estimation of the system stability margins. Compared with the eigenvalue analysis, the impedance-based analysis of the system allows design specifications to be readily derived for an arbitrary stability criterion (for example, the controllers can be designed such that the system would have an overall phase margin of 45 degrees) [35].

There are several stability criteria that can be used with the impedance-based analysis, including Middlebrook criterion, opposing component criterion, gain margin (GM) and phase margin (PM) criterion, ESAC, and several of their derivatives. A comprehensive review is provided in [35]. 
The main difference among various criteria is how conservative they are in the evaluation of the system stability margin. In this study, the phase margin approach (PM) is implemented in which the stability margins are defined by two line segments at an angle of $\pm \mathrm{PM}$ from the negative real axis. The system stability can be studied either from the eigenvalues of the system, or from the Nyquist plot of the system (the number of unstable poles of the system is equal to the number of encirclements of -1 by Nyquist contour). However, we are more interested in the system PM as an index for the system overall stability margin. In summary, the system stability is assessed by eigenvalue analysis, while the system stability margin is indicated by system PM.

The HVDC link can be modelled via two Thévenin equivalent source and load models as indicated in Figure 9. Note that, unlike the traditional impedance modeling approach (see [35]), there is no need to find mathematical expressions for the load and source impedances $\left(Z_{s}\right.$ and $\left.Z_{l}\right)$. The impedances can be directly obtained using the overall state-space model by defining appropriate input/output signals. For instance, referring to Figure 6 , the source admittance is obtained by defining a SISO system with the input of $\Delta V_{1}(\mathrm{~s})$ and the output of $\Delta i_{1}(\mathrm{~s})$ while only the state-space models of MMC 1 are considered. Then, $Z_{s}$ is the inverse of the source admittance. Using the same approach, $Z_{l}$ is calculated. Note that the cable impedance is integrated into the $Z_{l}$. Once the impedances are calculated, they can be written as

$$
Z_{s}(s)=\frac{N_{s}(s)}{D_{s}(s)} \text { and } Z_{l}(s)=\frac{N_{l}(s)}{D_{l}(s)}
$$

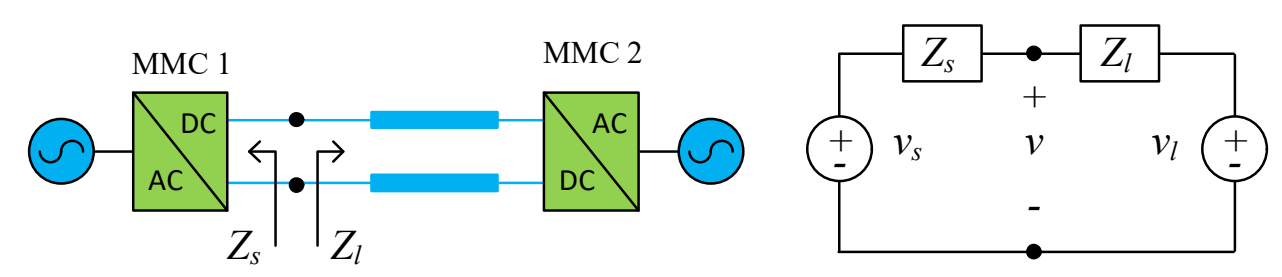

Figure 9. Thevenin equivalent source and load converter model.

From Figure 9, it is clear that

$$
v(s)=\frac{Z_{l}(s)}{Z_{s}(s)+Z_{l}(s)} v_{s}(s)+\frac{Z_{s}(s)}{Z_{s}(s)+Z_{l}(s)} v_{l}(s)
$$

Substitution of (11) into (12) and manipulating yields

$$
v(s)=\frac{N_{l}(s) D_{s}(s) v_{s}(s)+N_{s}(s) D_{l}(s) v_{l}(s)}{N_{l}(s) D_{s}(s)\left(1+Z_{s}(s) Y_{l}(s)\right)} .
$$

Assuming that the load and the source are stable systems if they operate individually (before interconnection), $N_{l}$ and $D_{s}$ would have no zeros in the right half-plane. The interconnection of the load and the source (complete HVDC link) is stable provided that $\left(1+Z_{s}(s) Y_{l}(s)\right)$ does not have any zeros in the right half-plane.

\section{System Analysis}

Once the system overall state-space model given by (9) and the impedance model presented by (13) are derived, the system stability and the interactions among control systems can be studied.

\subsection{System Stability Analysis}

The eigenvalue analysis is conducted on the overall state-space model of the HVDC link. The system has 43 state variables and therefore 43 eigenvalues, of which 11 states belong to MMC 1 , 11 states MMC 2, and 21 states are related to cable model. Assuming the cable length is $100 \mathrm{~km}$, 
the eigenvalues of the system are shown in Figure 10. In order to find critical modes, the damping ratio $(D)$ is defined for every eigenvalue $\left(\lambda_{i}\right)$ as

$$
D=-\operatorname{Re}\left(\lambda_{i}\right) / \operatorname{abs}\left(\lambda_{i}\right) .
$$

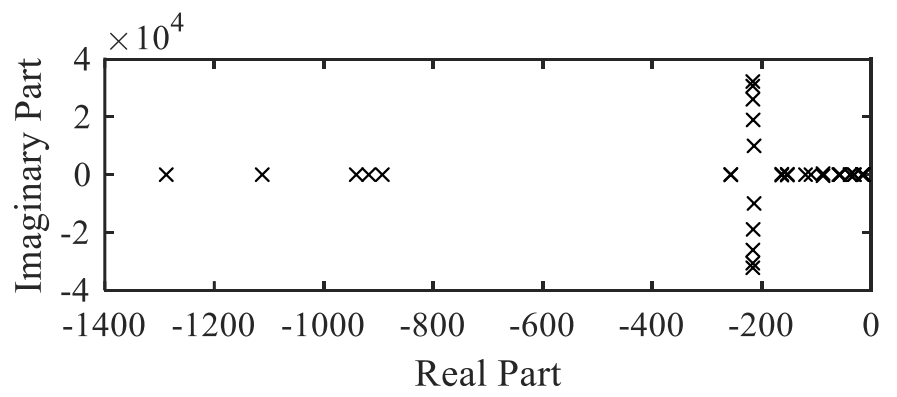

Figure 10. Eigenvalues of the HVDC link.

Among 43 system eigenvalues, 10 of them have a very low damping ratio (lower than 5\%). Hence, these 10 eigenvalues are considered to be the critical modes of the system. It is also noted that these critical modes have a high frequency with the order of $10^{4} \mathrm{rad} / \mathrm{s}$. In order to find the parameters of the system which contribute to the 10 critical modes, a normalized participation factor (nPF) analysis is conducted. As it is presented in Figure 11, the HVDC cable parameters (capacitor voltages and inductor currents related to the cable model) contribute to the eigenvalues 1 to 10 (critical modes with damping ratio lower than 5\%). The DC voltage PI controller of MMC 1 contributes to two eigenvalues with a damping ratio of about $22 \%$ and frequency near $400 \mathrm{rad} / \mathrm{s}$. Furthermore, four eigenvalues with the damping ratios of about $70 \%$ are related to the PLLs of the MMCs. The rest of the eigenvalues are properly damped.

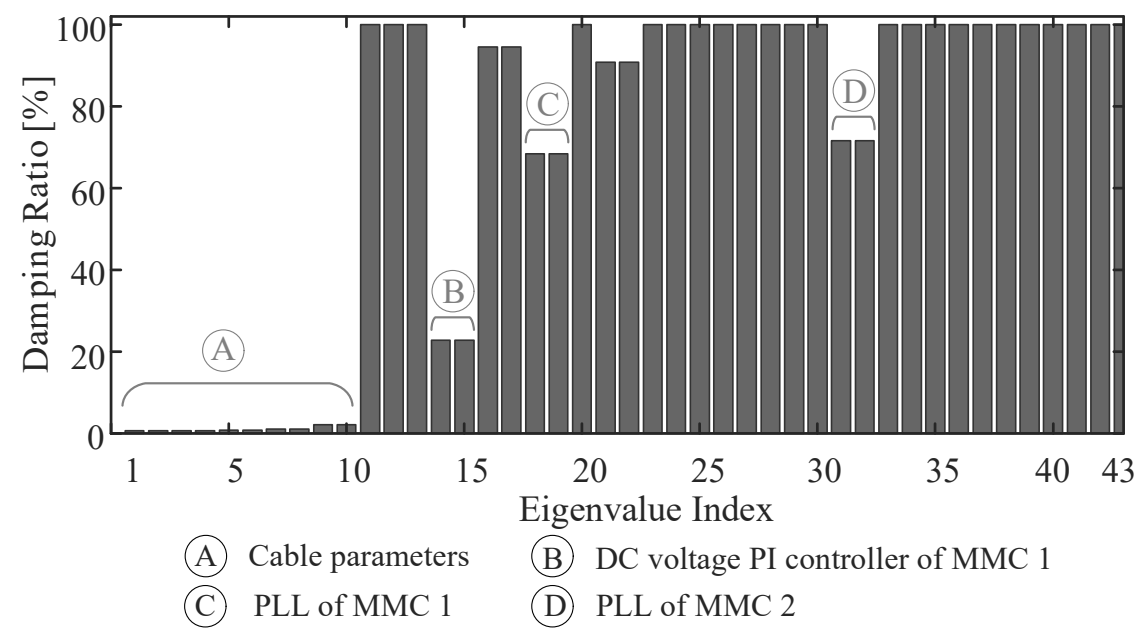

Figure 11. Damping ratios of the eigenvalues for the HVDC link with a cable length of $100 \mathrm{~km}$. The parameters contributing to the eigenvalues with a damping ratio lower than $70 \%$ are marked as $\mathrm{A}$, B, C, and D.

While the eigenvalue analysis and nPF are helpful for detecting not only the critical modes but also the main system components contributing to these critical modes, a Nyquist analysis can reveal how far the system is from instability. In fact, the Nyquist analysis and the associated phase/gain margins provide a single index that evaluates the system minimum stability margin. Referring to the impedance model of the HVDC link, the Nyquist plot of $\left(Z_{s}(s) Y_{l}(s)\right)$ is shown in Figure 12, which shows that the interconnection of the source and the load would be stable (for the cable length of $100 \mathrm{~km}$ ) and 
the system stability would have the minimum margins of $\mathrm{PM}=-22.6^{\circ}$ (at frequency $395 \mathrm{rad} / \mathrm{s}$ ) and $\mathrm{GM}=-16.1 \mathrm{~dB}$.

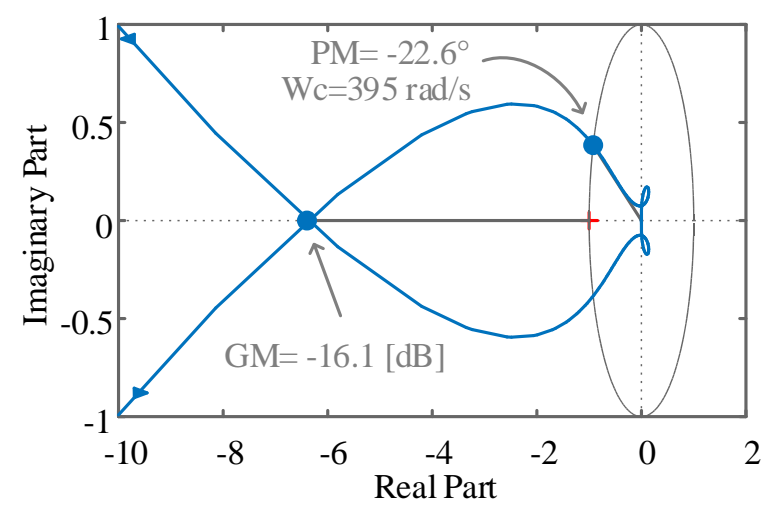

Figure 12. The Nyquist plot of $\left(Z_{s}(\mathrm{~s}) Y_{l}(s)\right)$ of the HVDC link with a cable length of $100 \mathrm{~km}$.

Since the cable parameters are very influential to the system stability, the system sensitivity is studied for the cable lengths ranged from $250 \mathrm{~km}$ to only $15 \mathrm{~km}$. As it is presented in Figure 13a, with the reduction of the cable length, the eigenvalues move towards the right half-plane, reducing system stability margin. This is also confirmed by impedance analysis. The system PM is shown in Figure 13b. For the cable length lower than $25 \mathrm{~km}$, the PM becomes positive and represents an unstable system. The system PM also shows saturation effects for longer cable lengths, and it changes slightly for cable lengths longer than $160 \mathrm{~km}$.
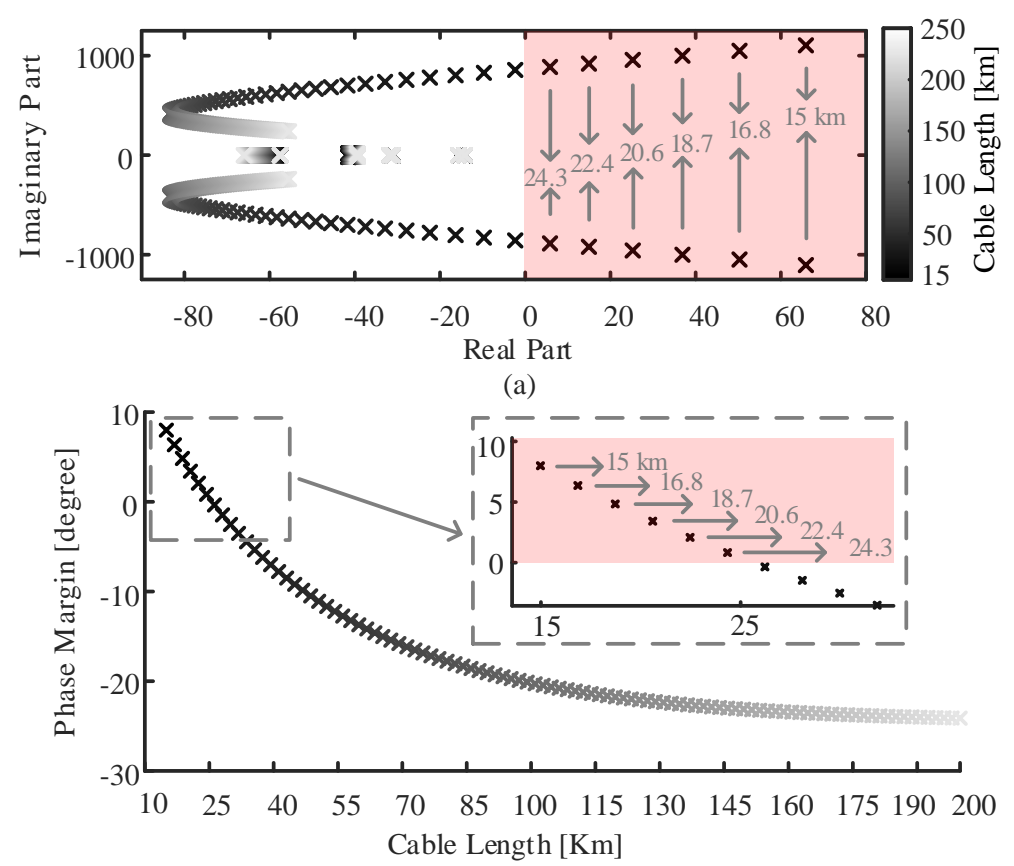

(b)

Figure 13. The sensitivity of the HVDC link to the cable length, (a) eigenvalue analysis, and (b) system phase margin.

The results obtained from the linear model analysis are validated via transient responses of the system nonlinear model. The transient response of the DC voltage and total energy control loops of MMC 1 are shown in Figure 14. The AC power injected into the AC grid by MMC 2 is increased by $20 \%$ at $t=0.4 \mathrm{~s}$ and then reduced again by the same amount at $t=0.65 \mathrm{~s}$. It is observed that for 
the shorter cable length, the system exhibits higher oscillations (lower damping and smaller PM), which is consistent with the linear analysis.

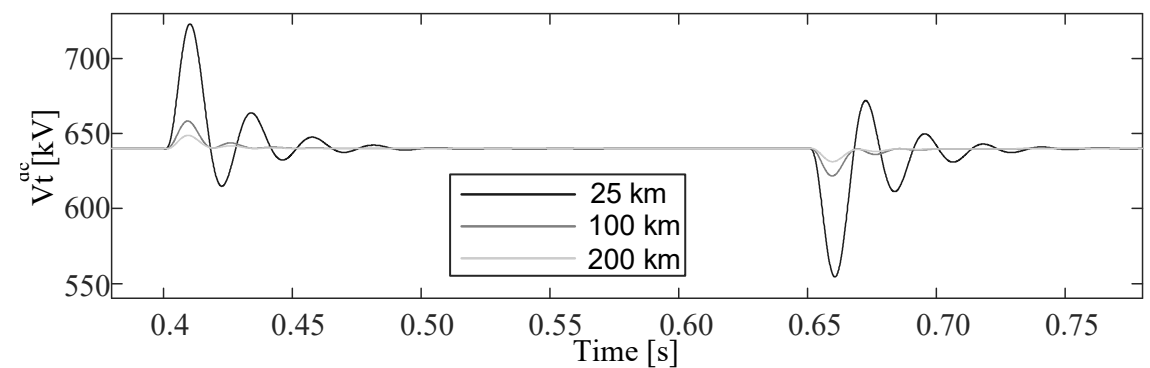

(a)

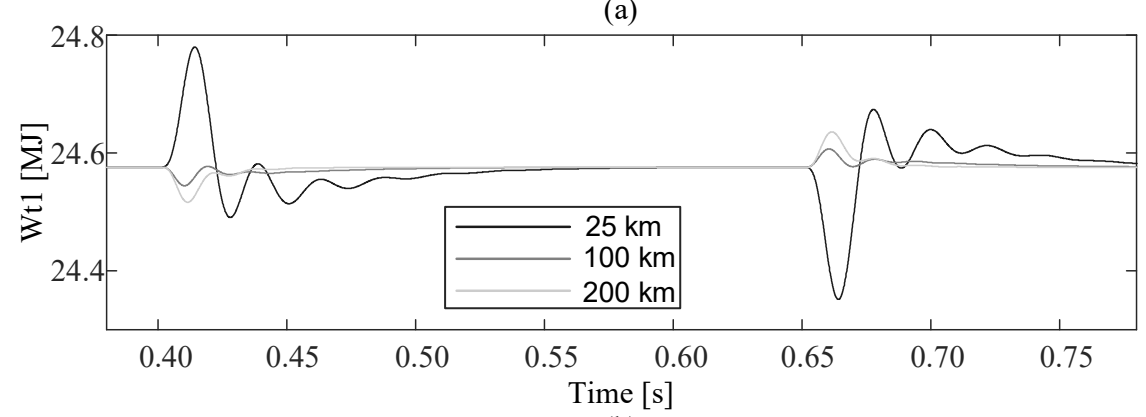

(b)

Figure 14. The transient response of (a) DC voltage and (b) the total energy control loops of MMC 1 for three different cable lengths.

\subsection{System Interactions}

Referring to Figure 4, there are four major cascaded control loops (two control loops per MMC) in the HVDC link: $V_{t}^{d c}, P_{2}, W_{t 1}$, and $W_{t 2}$. The control loops of MMC 1 interact with those of MMC 2 through the HVDC cable. For instance, a step change in the total energy of MMC 2 (step change in the reference $W_{t 2}^{*}$ ) would have impact on the DC voltage $V_{t}^{d c}$ of MMC 1 . In order to quantify these interactions, a frequency-dependant RGA analysis is conducted on the MIMO model shown in Figure 15, which includes the control loop references as the inputs, and the controlled variables as the outputs.

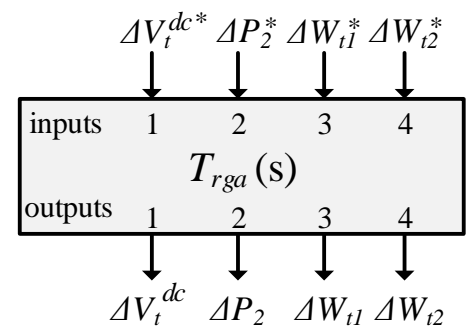

Figure 15. The MIMO model of the system used for relative gain array (RGA) analysis.

The results of the RGA analysis are presented in Figure 16. It can be observed that

- At low frequencies, all four control loops are strongly coupled with their own references, i.e., the RGA values between the controlled variables (such as $V_{t}^{d c}$ ) and the loop references (such as $V_{t}^{d c *}$ ) are the largest as compared with the RGA values related to other control loop references. Hence, the four control loops are well-designed for DC or low frequencies.

- $\quad$ The active power control loop $P_{2}$ does not interact with other three control loops $\left(V_{t}^{d c}, W_{t 1}\right.$, and $\left.W_{t 2}\right)$, and it is only coupled with its own reference. 
- At higher frequencies, the control loops begin to interact. As it can be seen from Figure 16, at the frequencies near $400 \mathrm{rad} / \mathrm{s}$, the RGA values increase, meaning that a controlled variable is importantly affected by the references of other control loops.

- Reference values should be changed with a limited bandwidth lower than $400 \mathrm{rad} / \mathrm{s}$ to avoid interactions between loops.

The RGA analysis identifies the frequency range in which the control loop interactions become significant. The control loops in the HVDC link highly interact with each other near frequency $400 \mathrm{rad} / \mathrm{s}$ (for the cable length of $100 \mathrm{~km}$ ). Interestingly, the system minimum PM (see Figure 12) happens near this frequency as well. It can be concluded that the interactions among control loops may have an influence on the system minimum PM.

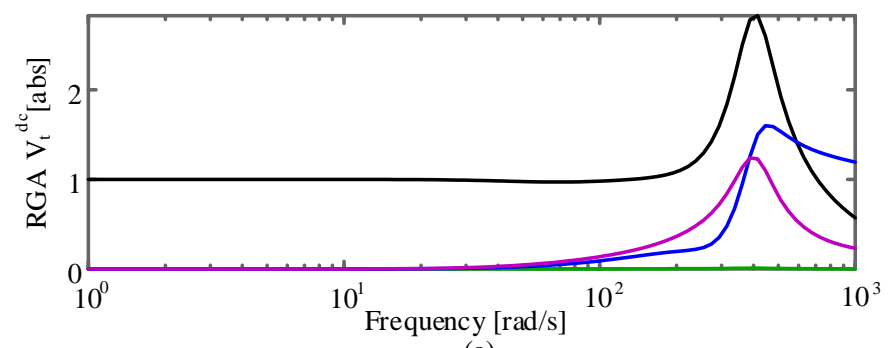

(a)

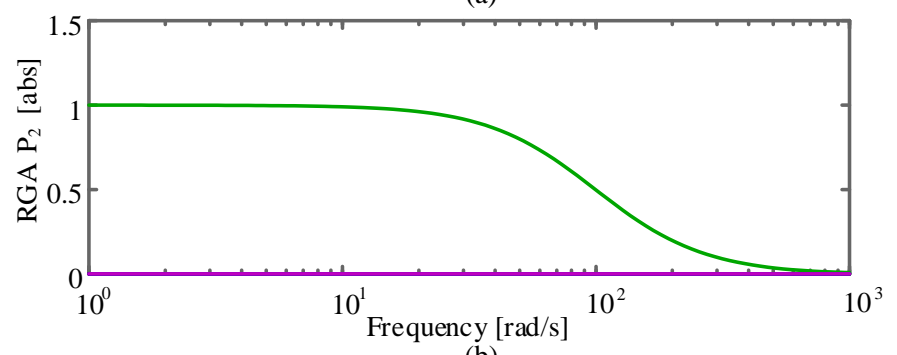

(b)

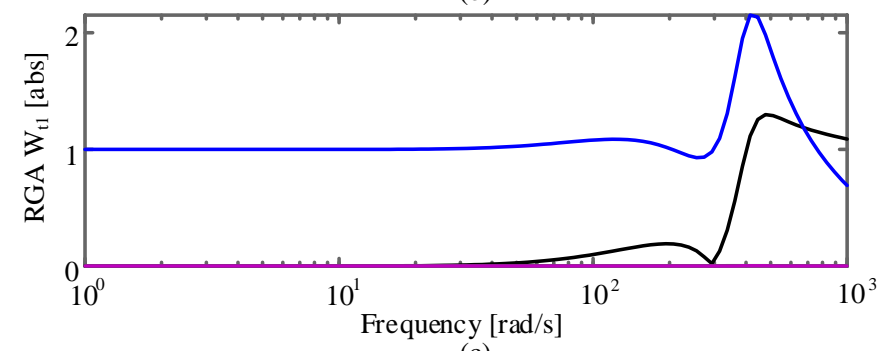

(c)

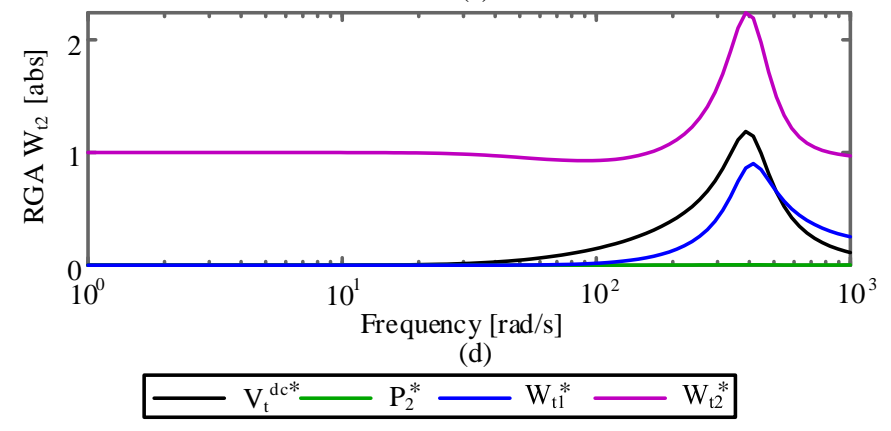

Figure 16. The RGA of four main control loops.

\section{DC Voltage Control Loop Design}

The results obtained in the previous section can be used to improve the system performance. The following conclusions have been extracted from the HVDC $100 \mathrm{~km}$ link case study: 
- The HVDC link has 10 eigenvalues (critical modes) with a damping ratio lower than 5\%, which are related to the cable parameters. The frequency of these modes are in order of $10^{4} \mathrm{rad} / \mathrm{s}$ (see Figure 11).

- There are two (conjugate) eigenvalues with a low damping ratio (about $22 \%$ ) that belong to the PI controller of the DC voltage control loop. Their frequency is near $400 \mathrm{rad} / \mathrm{s}$ (see Figure 11).

- The minimum PM of the HVDC link is $-22.6^{\circ}$ and occurs at the frequency near $400 \mathrm{rad} / \mathrm{s}$ (see Figure 12).

- The interactions among the control loops of the HVDC link begin to intensify at the frequencies near $400 \mathrm{rad} / \mathrm{s}$ (see Figure 16).

- The PI controller of the DC voltage controller should be adequately designed to improve the system dynamics since it is the loop that is mainly contributing to the system modes allocated close to the problematic frequency $400 \mathrm{rad} / \mathrm{s}$.

Then, assuming the cable length is already fixed at $100 \mathrm{~km}$, the dynamics of $V_{t}^{d c}$ control loop can be simply improved by finding the right gains that improve the control loop performance. Initially, the proportional and integral gains of the PI controller are set to 0.002 and 0.708 , respectively. These values are determined to make the outer control loop $\left(V_{t}^{d c}\right) 15$ times slower than the inner control loop. Then, both the proportional and integral gains of the PI controller are multiplied by a constant $k_{g}$ to find the case which is stable and has the largest PM. To do this, $k_{g}$ is varied from 0.1 to 10 .

The system dominant eigenvalues for the range of $k_{g}$ are shown in Figure 17a. The system is unstable for $k_{g}$ smaller than 0.2 and bigger than 5 . For all other values of $k_{g}$ between 0.2 to 5 the system is stable. The largest system PM occurs at $k_{g}$ equal to 0.55 as it is presented in Figure $17 \mathrm{~b}$. Thus, $k_{g}$ equal to 0.55 can be selected as an adequate design candidate.

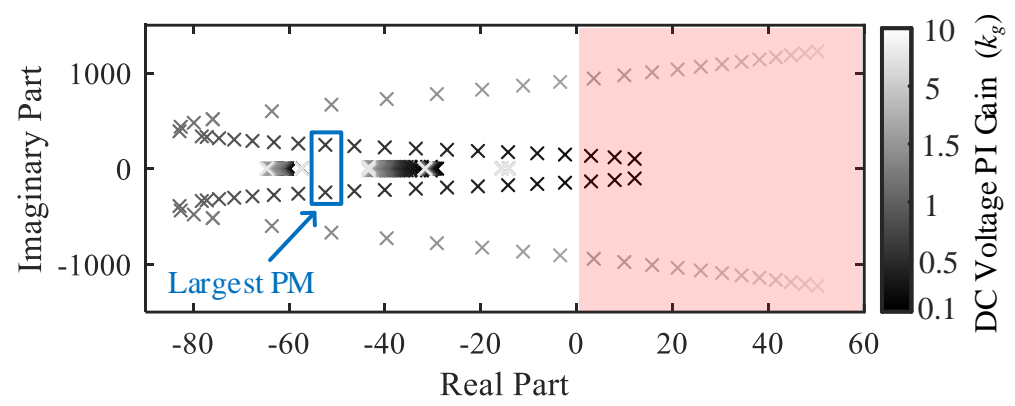

(a)

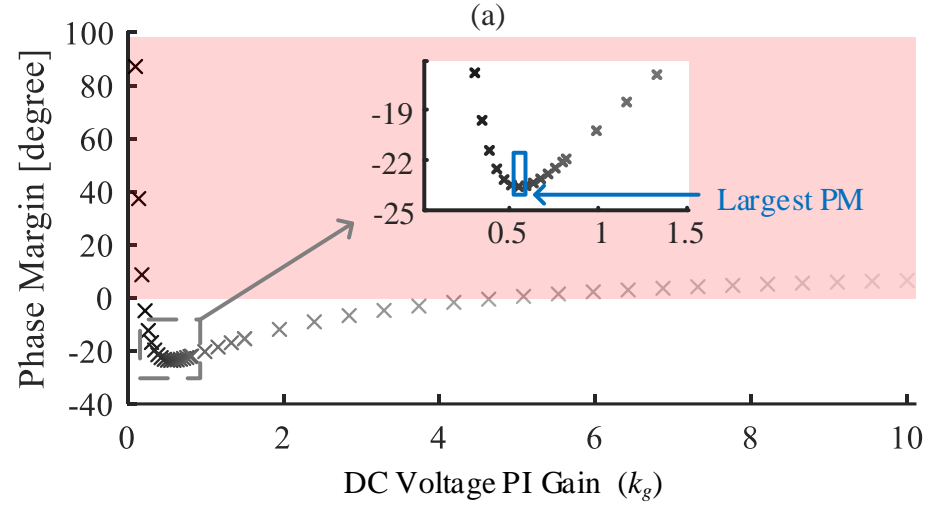

(b)

Figure 17. The impact of DC voltage PI gain $\left(k_{g}\right)$ on the system dynamics, (a) the system dominant eigenvalues, (b) the system phase margin.

The next step is to carry out RGA analysis in order to observe the level of control loop interactions for various values of $k_{g}$. The RGA values of $V_{t}^{d c}$ for the entire range of $k_{g}$ (from 0.1 to 10 ) are presented in Figure 18. Within two frequency bands, the RGA values exhibit large peaks, which indicate high level of interactions among control loops. The RGA values related to the design candidate $\left(k_{g}=0.55\right)$ 
should not have large peaks within the system frequency range which is confirmed from Figure 19. For the sake of clarity, the RGA analysis is conducted for fewer $k_{g}$ values $(0.2,0.55,2.5,5)$ within the defined stable range. Clearly, the RGA values for $k_{g}=0.55$ does not present large peaks, confirming the adequacy of the design candidate.

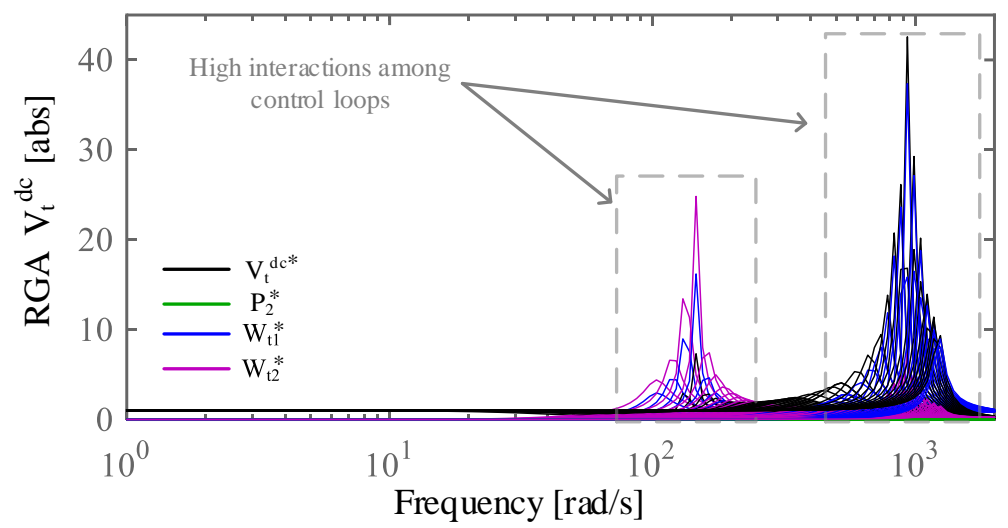

Figure 18. The RGA values of the DC voltage control loop for various PI controller gains $\left(k_{g}\right)$.
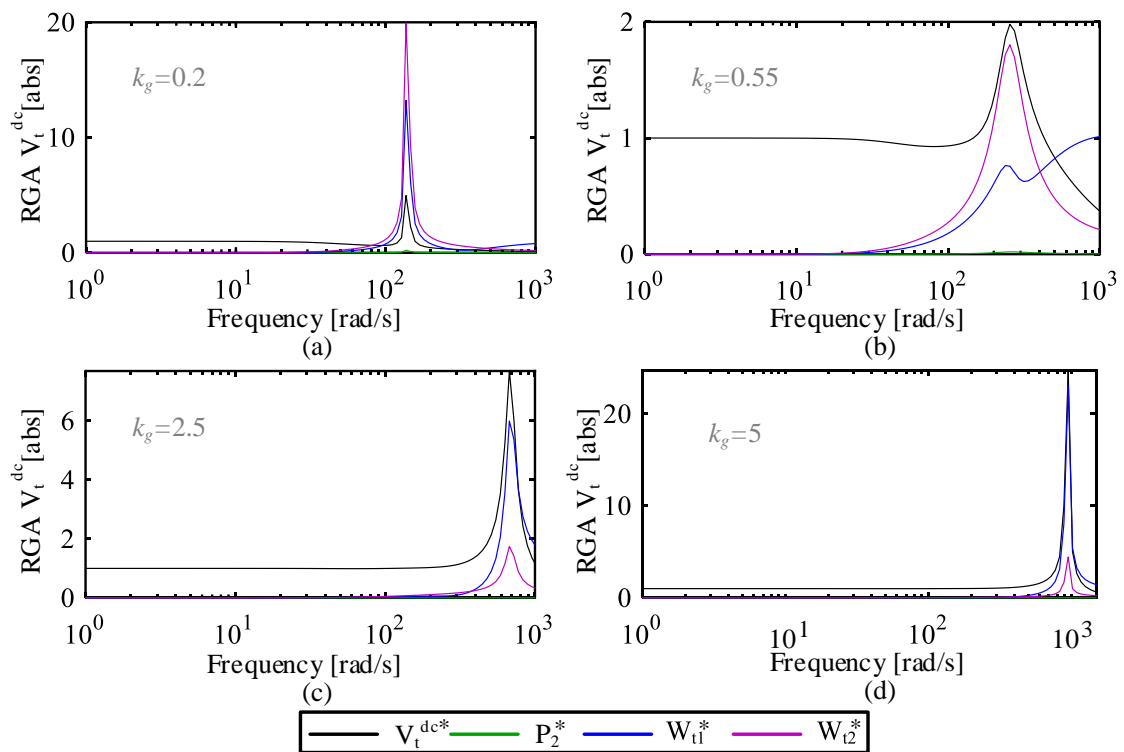

Figure 19. The RGA values of the DC voltage control loop for four values of $k_{g}$ : (a) $k_{g}=0.2,(\mathbf{b}) k_{g}=0.55$,

(c) $k_{g}=2.5$, and (d) $k_{g}=5$.

In order to verify the results obtained from the frequency-based design, a time-domain simulation is conducted on the HVDC link for the four values of $k_{g}$. The dynamic response of DC voltage for a $20 \%$ increase in the injected power $\left(P_{2}\right)$ is shown in Figure 20. The DC voltage is poorly damped for $k_{g}=0.2,2.5,5$, confirming that the system has low PM for these values. With regard to $k_{g}=0.55$ (design candidate), the DC voltage is less oscillatory, although showing a moderate overshoot. Note that the tuning of the DC voltage control loop is carried out considering the PM of the entire system, not only focusing on the DC voltage control loop. Thus, even though the DC voltage overshoot for the design case might be a bit higher compared to other $k_{g}$ values, it is able to maximize PM while reducing the interactions. 


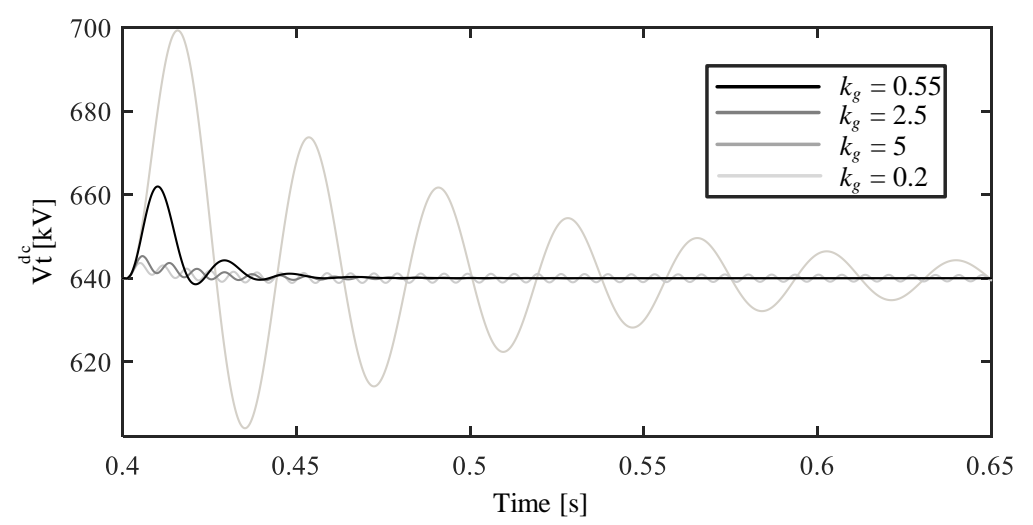

Figure 20. DC voltage dynamics for $k_{g}=0.2,0.55,2.5,5$.

\section{Conclusions}

In this paper, various small-signal analyses were conducted on an MMC-based HVDC link. Among several control loops in master and slave MMCs, the DC voltage control loop had the most adversary impact on the overall dynamics of the system. Using eigenvalue analysis and participation factors, it was revealed that two critical modes of the system were related to the PI controller of the DC voltage controller. Hence, this control loop was re-designed considering (1) the overall phase margin of the HVDC link, and (2) the level of interactions among the control loops of the master and slave MMCs. The PI gain of the DC voltage control loop was designed in such a way that the largest phase margin of the HVDC link was obtained. The phase margin was calculated from the Nyquist analysis conducted on the system impedance-based model. Moreover, using frequency-dependent RGA analysis, the level of interaction among control loops was minimized by the PI controller gain.

The RGA analysis, along with the participation factor, revealed that there exists a strong coupling among the control loops of master and slave MMCs. Therefore, for future studies, it is suggested to adopt a MIMO design approach in which all control loops are designed simultaneously and the system stability margin and the level of interactions can be mathematically formulated to a tractable optimization problem.

Author Contributions: conceptualization, O.G.-B., E.P.-A., S.D.T.; methodology, S.D.T., E.S.-S.; software, S.D.T., E.S.-S.; validation, S.D.T., E.P.-A., E.S.-S.; formal analysis, S.D.T., E.S.-S.; investigation, S.D.T.; resources, E.P.-A., E.S.-S.; data curation, E.P.-A., E.S.-S.; writing—original draft preparation, S.D.T.; writing-review and editing, E.P.-A., E.S.-S., O.G.-B.; visualization, S.D.T.; supervision, O.G.-B., E.P.-A.; project administration, O.G.-B.; funding acquisition, O.G.-B., E.P.-A. All authors have read and agreed to the published version of the manuscript.

Funding: This project has received funding from the European Union's Horizon 2020 research and innovation programme under the Marie Sklodowska-Curie grant agreement no. 765585. This document reflects only the author's views; the European Commission is not responsible for any use that may be made of the information it contains. This project has also received funding from FEDER/Ministerio de Ciencia, Innovación y Universidades Agencia Estatal de Investigación, Project RTI2018-095429-B-I00.

Acknowledgments: Eduardo Prieto-Araujo is a Serra Húnter Lecturer and Oriol Gomis-Bellmunt is an ICREA Academia researcher.

Conflicts of Interest: The authors declare no conflict of interest. 


\section{Appendix A}

The following Clarke (A1) and Park (A2) transformations have been used. Note that regarding Park transformation, the electrical machinery notation (qd0) is used

$$
\begin{aligned}
& \Theta^{\alpha \beta 0} \triangleq \frac{1}{3}\left[\begin{array}{ccc}
2 & -1 & -1 \\
0 & -\sqrt{3} & \sqrt{3} \\
1 & 1 & 1
\end{array}\right] \Theta^{a b c} \\
& \Theta^{q d 0} \triangleq \frac{2}{3}\left[\begin{array}{ccc}
\cos (\theta) & \cos \left(\theta-\frac{2 \pi}{3}\right) & \cos \left(\theta+\frac{2 \pi}{3}\right) \\
\sin (\theta) & \sin \left(\theta-\frac{2 \pi}{3}\right) & \sin \left(\theta+\frac{2 \pi}{3}\right) \\
\frac{1}{2} & \frac{1}{2} & \frac{1}{2}
\end{array}\right] \Theta^{a b c}
\end{aligned}
$$

MMCs and AC grids parameters are given in Table A1, while the HVDC cable parameters are provided in Table A2.

Table A1. MMC and AC grid parameters.

\begin{tabular}{lccc}
\hline Parameter & Symbol & Value & Units \\
\hline Rated (base) active power & $P_{N}$ & 500 & $\mathrm{MW}$ \\
Rated (base) AC-side voltage & $U_{N}$ & 320 & $\mathrm{kV}$ \\
Rated (base) DC-side voltage & $V_{N}^{\mathrm{dc}}$ & \pm 320 & $\mathrm{kV}$ \\
Grid short-circuit ratio & $\mathrm{SCR}$ & 10 & - \\
Coupling impedance & $R_{s}+\mathrm{j} L_{s}$ & $0.01+\mathrm{j} 0.2$ & $\mathrm{pu}$ \\
Arm reactor impedance & $R_{a}+\mathrm{j} L_{a}$ & $0.01+\mathrm{j} 0.2$ & $\mathrm{pu}$ \\
Converter submodules per arm & $N_{\mathrm{arm}}$ & 400 & - \\
Average submodule voltage & $V_{\mathrm{SM}}$ & 1.6 & $\mathrm{kV}$ \\
Submodule capacitance & $C_{\mathrm{SM}}$ & 8 & $\mathrm{mF}$ \\
\hline
\end{tabular}

Table A2. Cable parameters

\begin{tabular}{lccccc}
\hline Symbol & Value & Units & Symbol & Value & Units \\
\hline$r_{1}$ & 0.1265 & $\Omega / \mathrm{km}$ & $l_{1}$ & 0.2644 & $\mathrm{mH} / \mathrm{km}$ \\
$r_{2}$ & 0.1504 & $\Omega / \mathrm{km}$ & $l_{2}$ & 7.2865 & $\mathrm{mH} / \mathrm{km}$ \\
$r_{3}$ & 0.0178 & $\Omega / \mathrm{km}$ & $l_{3}$ & 3.6198 & $\mathrm{mH} / \mathrm{km}$ \\
$c$ & 0.1616 & $\mu \mathrm{F} / \mathrm{km}$ & $g$ & 0.1015 & $\mu \mathrm{S} / \mathrm{km}$ \\
\hline
\end{tabular}

\section{References}

1. Khazaei, J.; Beza, M.; Bongiorno, M. Impedance Analysis of Modular Multi-Level Converters Connected to Weak AC Grids. IEEE Trans. Power Syst. 2018, 33, 4015-4025. doi:10.1109/TPWRS.2017.2779403. [CrossRef]

2. Vidal-Albalate, R.; Forner, J. Modeling and Enhanced Control of Hybrid Full Bridge-Half Bridge MMCs for HVDC Grid Studies. Energies 2020, 13, 180. doi:10.3390/en13010180. [CrossRef]

3. Tu, Q.; $\mathrm{Xu}, \mathrm{Z} . ; \mathrm{Xu}, \mathrm{L}$. Reduced Switching-Frequency Modulation and Circulating Current Suppression for Modular Multilevel Converters. IEEE Trans. Power Deliv. 2011, 26, 2009-2017. doi:10.1109/TPWRD.2011.2115258. [CrossRef]

4. Harnefors, L.; Antonopoulos, A.; Norrga, S.; Angquist, L.; Nee, H. Dynamic Analysis of Modular Multilevel Converters. IEEE Trans. Ind. Electron. 2013, 60, 2526-2537. doi:10.1109/TIE.2012.2194974. [CrossRef]

5. Angquist, L.; Antonopoulos, A.; Siemaszko, D.; Ilves, K.; Vasiladiotis, M.; Nee, H. Open-Loop Control of Modular Multilevel Converters Using Estimation of Stored Energy. IEEE Trans. Ind. Appl. 2011, 47, $2516-2524$. doi:10.1109/TIA.2011.2168593. [CrossRef]

6. Jamshidifar, A.; Jovcic, D. Small-Signal Dynamic DQ Model of Modular Multilevel Converter for System Studies. IEEE Trans. Power Deliv. 2016, 31, 191-199. doi:10.1109/TPWRD.2015.2478489. [CrossRef] 
7. Bergna, G.; Suul, J.A.; D'Arco, S. State-space modelling of modular multilevel converters for constant variables in steady-state. In Proceedings of the 2016 IEEE 17th Workshop on Control and Modeling for Power Electronics (COMPEL), Trondheim, Norway, 27-30 June 2016; pp. 1-9. doi:10.1109/COMPEL.2016.7556695. [CrossRef]

8. Prieto-Araujo, E.; Junyent-Ferré, A.; Collados-Rodríguez, C.; Clariana-Colet, G.; Gomis-Bellmunt, O. Control design of Modular Multilevel Converters in normal and AC fault conditions for HVDC grids. Electr. Power Syst. Res. 2017, 152, 424-437. doi:10.1016/j.epsr.2017.06.020. [CrossRef]

9. Antonopoulos, A.; Angquist, L.; Nee, H. On dynamics and voltage control of the Modular Multilevel Converter. In Proceedings of the 2009 13th European Conference on Power Electronics and Applications, Barcelona, Spain, 8-10 September 2009; pp. 1-10.

10. Freytes, J.; Akkari, S.; Dai, J.; Gruson, F.; Rault, P.; Guillaud, X. Small-signal state-space modeling of an HVDC link with modular multilevel converters. In Proceedings of the 2016 IEEE 17th Workshop on Control and Modeling for Power Electronics (COMPEL), Trondheim, Norway, 27-30 June 2016; pp. 1-8. doi:10.1109/COMPEL.2016.7556693. [CrossRef]

11. Bergna-Diaz, G.; Suul, J.A.; D'Arco, S. Energy-Based State-Space Representation of Modular Multilevel Converters with a Constant Equilibrium Point in Steady-State Operation. IEEE Trans. Power Electron. 2018, 33, 4832-4851. doi:10.1109/TPEL.2017.2727496. [CrossRef]

12. Sharifabadi, K.; Harnefors, L.; Nee, H.; Norrga, S.; Teodorescu, R. Modulation and Submodule Energy Balancing. In Design, Control, and Application of Modular Multilevel Converters for HVDC Transmission Systems; IEEE: Piscataway, NJ, USA, 2016; pp. 232-271.doi:10.1002/9781118851555.ch5. [CrossRef]

13. Freytes, J.; Akkari, S.; Rault, P.; Belhaouane, M.M.; Gruson, F.; Colas, F.; Guillaud, X. Dynamic Analysis of MMC-Based MTDC Grids: Use of MMC Energy to Improve Voltage Behavior. IEEE Trans. Power Deliv. 2019, 34, 137-148. doi:10.1109/TPWRD.2018.2868878. [CrossRef]

14. Sánchez-Sánchez, E.; Prieto-Araujo, E.; Junyent-Ferré, A.; Gomis-Bellmunt, O. Analysis of MMC Energy-Based Control Structures for VSC-HVDC Links. IEEE J. Emerg. Sel. Top. Power Electron. 2018, 6, 1065-1076. doi:10.1109/JESTPE.2018.2803136. [CrossRef]

15. Agbemuko, A.J.; Domínguez-García, J.L.; Prieto-Araujo, E.; Gomis-Bellmunt, O. Dynamic modelling and interaction analysis of multi-terminal VSC-HVDC grids through an impedance-based approach. Int. J. Electr. Power Energy Syst. 2019, 113, 874-887. doi:10.1016/j.ijepes.2019.06.029. [CrossRef]

16. Bayo-Salas, A.; Beerten, J.; Rimez, J.; Van Hertem, D. Analysis of control interactions in multi-infeed VSC HVDC connections. IET Gener. Transm. Distrib. 2016, 10, 1336-1344. doi:10.1049/iet-gtd.2015.0876. [CrossRef]

17. Bergna-Diaz, G.; Freytes, J.; Guillaud, X.; D'Arco, S.; Suul, J.A. Generalized Voltage-Based State-Space Modeling of Modular Multilevel Converters With Constant Equilibrium in Steady State. IEEE J. Emerg. Sel. Top. Power Electron. 2018, 6, 707-725. doi:10.1109/JESTPE.2018.2793159. [CrossRef]

18. Sakinci, O.C.; Beerten, J. Generalized Dynamic Phasor Modeling of the MMC for Small-Signal Stability Analysis. IEEE Trans. Power Deliv. 2019, 34, 991-1000. doi:10.1109/TPWRD.2019.2898468. [CrossRef]

19. Deore, S.R.; Darji, P.B.; Kulkarni, A.M. Dynamic phasor modeling of Modular Multi-level Converters. In Proceedings of the 2012 IEEE 7th International Conference on Industrial and Information Systems (ICIIS), Chennai, India, 6-9 August 2012; pp. 1-6.doi:10.1109/ICIInfS.2012.6304792. [CrossRef]

20. Li, T.; Gole, A.; Zhao, C. Stablity of a modular multilevel converter based HVDC system considering DC side connection. In Proceedings of the 12th IET International Conference on AC and DC Power Transmission (ACDC 2016), Beijing, China, 28-29 May 2016; pp. 1-6. doi:10.1049/cp.2016.0401. [CrossRef]

21. Chen, H.; Hu, P.; Yu, Y.; Zhu, X. An advanced small-signal model of multi-terminal MMC-HVDC for power systems stability analysis based on dynamic phasors. In Proceedings of the 2017 IEEE Power Energy Society General Meeting, Chicago, IL, USA, 16-20 July 2017; pp. 1-5. doi:10.1109/PESGM.2017.8273844. [CrossRef]

22. Guo, C.; Yang, J.; Zhao, C. Investigation of Small-Signal Dynamics of Modular Multilevel Converter Under Unbalanced Grid Conditions. IEEE Trans. Ind. Electron. 2019, 66, 2269-2279. doi:10.1109/TIE.2018.2831193. [CrossRef]

23. Lyu, J.; Cai, X.; Molinas, M. Impedance modeling of modular multilevel converters. In Proceedings of the IECON 2015-41st Annual Conference of the IEEE Industrial Electronics Society, Yokohama, Japan, 9-12 November 2015; pp. 000180-000185. doi:10.1109/IECON.2015.7392096. [CrossRef] 
24. Wu, H.; Wang, X.; Kocewiak, L.; Harnefors, L. AC Impedance Modeling of Modular Multilevel Converters and Two-Level Voltage-Source Converters: Similarities and Differences. In Proceedings of the 2018 IEEE 19th Workshop on Control and Modeling for Power Electronics (COMPEL), Padova, Italy, 25-28 June 2018; pp. 1-8. doi:10.1109/COMPEL.2018.8459952. [CrossRef]

25. Shi, X.; Wang, Z.; Liu, B.; Li, Y.; Tolbert, L.M.; Wang, F. DC impedance modelling of a MMC-HVDC system for DC voltage ripple prediction under a single-line-to-ground fault. In Proceedings of the 2014 IEEE Energy Conversion Congress and Exposition (ECCE), Pittsburgh, PA, USA, 14-18 September 2014, pp. 5339-5346. doi:10.1109/ECCE.2014.6954133. [CrossRef]

26. Uddin, W.; Zeb, K.; Adil Khan, M.; Ishfaq, M.; Khan, I.; Islam, S.U.; Kim, H.J.; Park, G.S.; Lee, C. Control of Output and Circulating Current of Modular Multilevel Converter Using a Sliding Mode Approach. Energies 2019, 12, 4084. doi:10.3390/en12214084. [CrossRef]

27. Sánchez-Sánchez, E.; Prieto-Araujo, E.; Gomis-Bellmunt, O. Multi-terminal HVDC voltage droop control design considering DC grid, AC grid and MMC dynamics. In Proceedings of the 13th IET International Conference on AC and DC Power Transmission (ACDC 2017), Manchester, UK, 14-16 February 2017; pp. 1-6. doi:10.1049/cp.2017.0052. [CrossRef]

28. Gnanarathna, U.N.; Gole, A.M.; Jayasinghe, R.P. Efficient Modeling of Modular Multilevel HVDC Converters (MMC) on Electromagnetic Transient Simulation Programs. IEEE Trans. Power Deliv. 2011, 26, 316-324. [CrossRef]

29. Yang, H.; Dong, Y.; Li, W.; He, X. Average-Value Model of Modular Multilevel Converters Considering Capacitor Voltage Ripple. IEEE Trans. Power Deliv. 2017, 32, 723-732. [CrossRef]

30. Peralta, J.; Saad, H.; Dennetiere, S.; Mahseredjian, J.; Nguefeu, S. Detailed and Averaged Models for a 401-Level MMC-HVDC System. IEEE Trans. Power Deliv. 2012, 27, 1501-1508. [CrossRef]

31. Junyent-Ferré, A.; Clemow, P.; Merlin, M.M.C.; Green, T.C. Operation of HVDC Modular Multilevel Converters under DC pole imbalances. In Proceedings of the 2014 16th European Conference on Power Electronics and Applications, Piscataway, NJ, USA, 26-28 August 2014; pp. 1-10. doi:10.1109/EPE.2014.6911011. [CrossRef]

32. Bergna, G.; Suul, J.A.; D'Arco, S. Impact on small-signal dynamics of using circulating currents instead of AC-currents to control the DC voltage in MMC HVDC terminals. In Proceedings of the 2016 IEEE Energy Conversion Congress and Exposition (ECCE), Milwaukee, IL, USA, 18-22 September 2016; pp. 1-8. doi:10.1109/ECCE.2016.7855182. [CrossRef]

33. Liu, W.; Liang, J.; de Morais Dias Campos, N.; Bhardwaj, V.; Beerten, J.; Van Hertem, D.; Ergun, H.; Tavakoli, S.; Prieto-Araujo, E.; Gomis-Bellmunt, O.; et al. Dynamic Converter Interactions and the Feasibility of Different Software Routines to Represent the Problems; InnoDC Deliverable 3.2. 2019. pp. 1-66. Available online: https:/ /innodc.org/wp-content/uploads/sites/11/2019/03/Dynamic-converter-interactions-anddifferent-software-Feb-2019.pdf (accessed on 1 March 2020).

34. Beerten, J.; D'Arco, S.; Suul, J.A. Frequency-dependent cable modelling for small-signal stability analysis of VSC-HVDC systems. IET Gener. Transm. Distrib. 2016, 10, 1370-1381. doi:10.1049/iet-gtd.2015.0868. [CrossRef]

35. Sudhoff, S.D.; Glover, S.F.; Lamm, P.T.; Schmucker, D.H.; Delisle, D.E. Admittance space stability analysis of power electronic systems. IEEE Trans. Aerosp. Electron. Syst. 2000, 36, 965-973. doi:10.1109/7.869516. [CrossRef]

(C) 2020 by the authors. Licensee MDPI, Basel, Switzerland. This article is an open access article distributed under the terms and conditions of the Creative Commons Attribution (CC BY) license (http://creativecommons.org/licenses/by/4.0/). 